\title{
The miracle of the mould
}

\section{Howard Florey and colleagues overcame great obstacles to isolate penicillin.}

\section{The Mould in Dr Florey's Coat: The Remarkable True Story of the Penicillin Miracle \\ by Eric Lax \\ Little, Brown: 2004. 288 pp. 116.99 \\ William Shaw}

Well-researched and readable accounts of medical science and disease are always welcome. The first thing to note about this new work by Eric Lax, whose earlier efforts have been a well-regarded biography of Woody Allen and an engaging account of cancer chemotherapy, is that its title promises a great deal - and does so rather late in the day.

There is little doubt that, after more than half a century of personal reflections and scholarship, the story of the emergence of penicillin as a life-saving medicine remains remarkable - not least for the obstacles overcome and for the personalities of the trio of Nobel laureates involved: Alexander Fleming, Howard Florey and Ernst Chain. But promise of a true story begs the question of what has been on offer since 1945. And was there a miracle? Well, nearly, at least in the sense that the small team assembled by Florey at the Sir William Dunn School of Pathology in Oxford, UK, in the dark and difficult early years of the Second World War, hardly seemed like a research unit likely to isolate and purify a substance active at very high dilution and alreadyknown to be unstable. There were also long odds on their demonstrating its safety and efficacy, as well on their ability to marshall pharmaceutical forces in a drowsy America - while German bombs were falling on Britain each night.

Two items stand out in Lax's introduction, the first being a brief account of the case of Anne Miller, treated successfully in March 1942 at New Haven Hospital for streptococcal sepsis with penicillin from Merck, the first systemic cure in the United States and a trigger to accelerated production there. It was her obituary in the New York Times 57 years later that sparked Lax's interest. The second item, which flags a story that he develops, reads: "There are four people at the heart of the penicillin story: Fleming, Florey, Heatley, and Ernst Chain."

Norman Heatley's critical role in the proving of penicillin was not recognized until 1990, when Oxford awarded him an
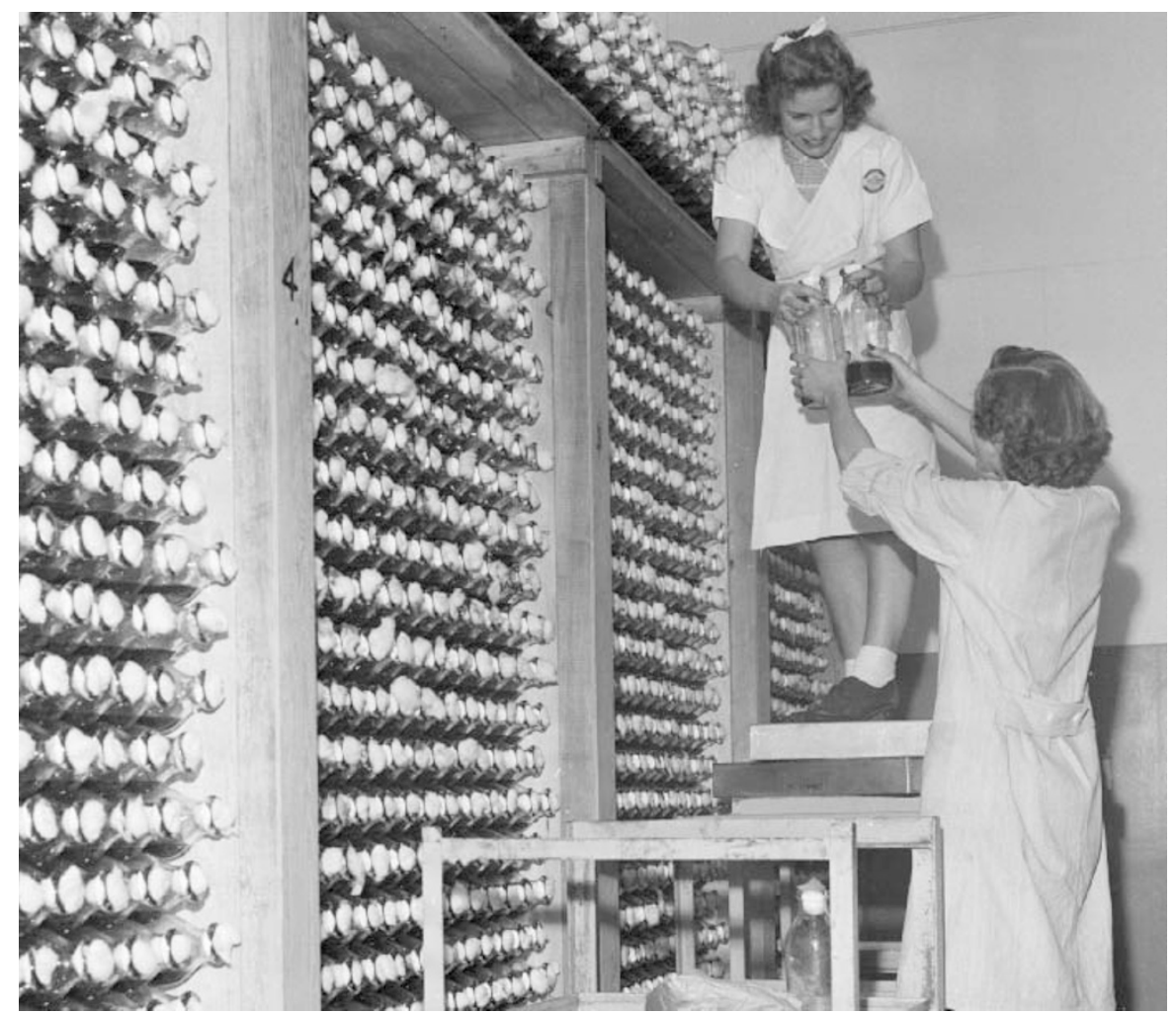

Norman Heatley (below left) oversaw the mass production of penicillin in 1940s America.

honorary doctorate of medicine, the first non-medical person to be so honoured. Although several authors have sought Heatley's recollections, few have had access to his notes and diaries, which cover the early years of the penicillin story. Lax is the first to put Heatley's perceptions front and centre, from long interviews with him and careful scrutiny of his writings. That Lax felt compelled to do so owes less to a deliberate lack of emphasis on Heatley's role by earlier writers than it does to Heatley's self-effacement. In fact, the two definitive biographies of Florey, by Gwyn Macfarlane and Trevor Williams, give Heatley much credit, although Ronald Clark in his Life of Ernst Chain focuses more on his larger-than-life title character.

In addition to drawing heavily on a dozen or more standard references on the early history of penicillin, including those noted above, Lax has made good use of a wide range of primary material. This includes UK sources, such as the Florey archives at the Royal Society, Chain's papers in the Wellcome Library and those of Edward Abraham in Oxford's Bodleian Library, and archives from farther afield, such as the Yale papers of John Fulton, Florey's close friend and champion, the archives of the Rockefeller Foundation in New York, and the Nobel archives in Stockholm. The author's efforts to explain biological or chemical concepts or procedures to non-scientists are less successful, however, and occasionally wrong. But this detracts little from an engrossing story and is unlikely to lead lay readers astray.

Although The Mould in Dr Florey's Coat is hardly a fresh look at a familiar subject, it does break new ground in providing a more balanced view, one that attempts to reconcile competing claims, either of the principals or their biographers. There are splendid opening chapters on each of the four players: "The Quiet Scot” (Fleming), “The Rough Colonial Genius" (Florey), "The Temperamental Continental" (Chain) and "The Micro Master" (Heatley). Then the narrative begins, slowly at first, accelerating as penicillin begins to arrive from America - a trickle initially, but in sufficient amounts by 1943 to reach military surgeons in the field, with Florey in North Africa advising on its use.

But the best of the story covers the early years from 1939 to late 1942, when nothing was certain, including the success of Florey and Heatley's journey to the United States to seek support for the industrial production of 
penicillin. Perhaps it was then that Penicillium notatum was in Florey's coat pocket, or even, from Heatley's account of a practice he suggested earlier, present as spores rubbed on the lapels of their jackets for safekeeping.

The virtue of Lax's approach is that it focuses not only on members of the Oxford team and their relationships with one another but also on the great and the good of Britain and America, who in one way or another helped to make it happen, notwithstanding frequent lapses in their comprehension of the staggering difficulties facing Florey. Lax helps modern readers understand that the 'proof of principle' mouse experiments took place as Dunkirk was being evacuated, and that the consequent push to enhance the supply of penicillin in Oxford coincided with the onset of the Blitz.

Florey's complicated personal life from 1940 onwards is also part of the story. With their children evacuated to the United States from 1941, Ethel and Howard Florey struggled to work out how to remain together while Howard continued his demanding professional life, Ethel found ways to live with deafness and contribute to clinical work with penicillin in Oxford, and - not part of the agreement - Howard turned to his laboratory associate Margaret Jennings for affection, said by one observer to be "one of the worst-kept secrets in Oxford".

There is ample evidence to support Lax's decision to bring Heatley to the foreground, closer to Florey than to Chain. Florey not only valued Heatley's unquestioned experimental skills, gift for improvization and intelligence, he trusted and depended upon him. Heatley's respect for, and commitment to, "the Professor" were unqualified. Lax makes it clear that the chemistry of their relationship enabled Florey to focus on the big issues, channelling his energy and broad intelligence into important pursuits. Thus, when he could leave nothing to chance, Florey turned to Heatley, rather than Chain, for his travelling companion on the Pan American clipper to New York from Lisbon in July 1941, to join him for virtually every meeting in America with industry or government figures, and leaving him behind for a full year to assist and advise the parties who would undertake the large-scale production of penicillin.

Sadly, Heatley never had the opportunity to read Lax's account, as he died on 5 January 2004, just before his 93rd birthday. Had he still been alive, one can imagine him objecting that far too much attention had come his way of late, that luck had always played a large role in the enterprise, and that he agreed with Pasteur: being prepared to recognize good fortune, and having the wits to act upon it, was sufficient.

William Shaw is professor emeritus of biochemistry and chemical microbiology at the University of

Leicester,UK.e-mail:bill.shaw@rcn.com

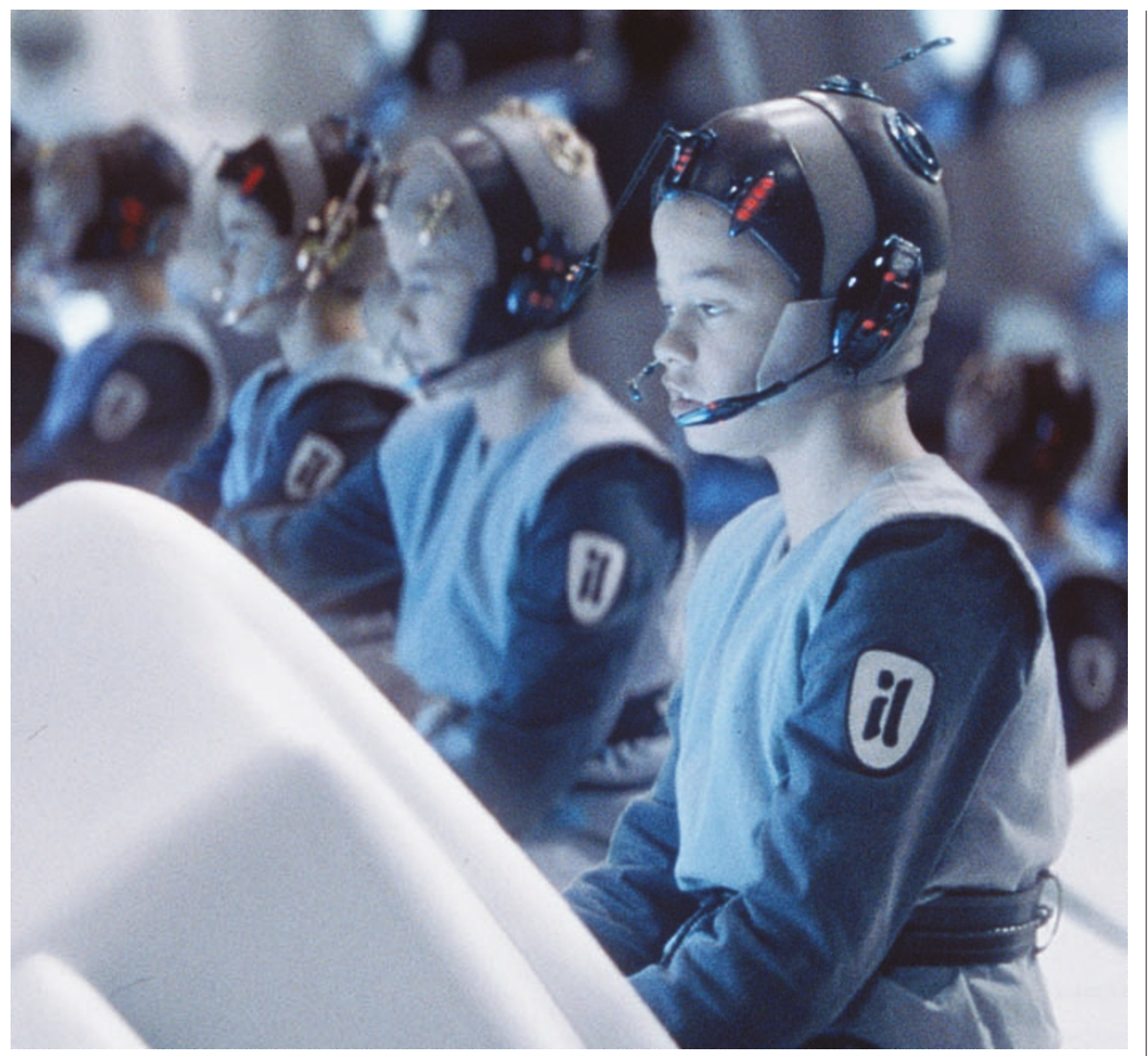

A real risk? Cloning is used to create warriors in Star Wars Episode II: Attack of the Clones.

\section{A clear view of cloning}

\section{A Clone of Your Own? The Science and Ethics of Cloning}

by Arlene Judith Klotzko

Oxford University Press: 2004. 162 pp. $£ 12.99$

\section{John Harris and Tuija Takala}

For members of the general public confused by the heated debate generated by human cloning, A Clone of Your Own? does an admirable job in explaining many of the complicated ethical and scientific issues without giving way to academic jargon. Drawing from literature, the visual arts, films and her personal experiences, Arlene Judith Klotzko has created a comprehensible overview of cloning.

Klotzko tells us about the early experiments that Aristotle did with chicken embryos; about a German scientist, Hans Spemann, who figured out the theory of cloning some sixty years before we actually succeeded in cloning mammals; about Dolly, the first cloned sheep, and other work done at Edinburgh's Roslin Institute; and the current successes and failures in attempts to clone mammals. She explains the basics of embryology and provides an overview of stem-cell research.

The book paints a picture of human cloning as a worthwhile enterprise. Klotzko lists the various potential benefits that therapeutic cloning could have, and explains why we might have reservations about reproductive cloning, even if it should not be banned completely. She also, following several others, clarifies many of the common misconceptions concerning the identity of clones, and puts in plain words the restricted effect that genes have in shaping the kind of people we become.

For a book with radical pretensions, Klotzko's arguments are restrained in their defence of human reproductive cloning she is impressed by the supposed risks entailed. One of the major objections to any current attempt to clone a human is that, in the case of Dolly, only one clone was successfully produced after 277 attempts. Cloning is inefficient and wastes many embryos. But embryo wastage cannot be an objection to reproductive cloning for those who accept natural reproduction - after all, about $80 \%$ of embryos perish in natural reproduction. For every live birth, 3-5 embryos are created only to die.

We must remember that giving birth in the normal way isn't safe for the mother or the child. It is so risky that early abortion is safer for the mother than childbirth. Moreover, $3-5 \%$ of babies born have some abnormality. So the safety of reproductive cloning is at best a contingent argument that fails utterly if cloning could be made safe. Furthermore, the safety argument is interestingly 